\title{
Interchanged Limb Electrodes by ECG
}

\section{Finding}

National Cancer Institute

\section{Source}

National Cancer Institute. Interchanged Limb Electrodes by ECG Finding. NCI Thesaurus.

Code C114150.

An electrocardiographic recording in which two or more of the limb electrodes are

switched resulting in improper representation of the affected leads. (CDISC) 